\title{
Peramalan Kunjungan Wisatawan Mancanegara Menggunakan Generalized Regression Neural Networks
}

\author{
Sri Herawati \\ Fakultas Teknik, Universitas Trunojoyo \\ Jl. Raya Telang Po. Box 2 Kamal Bangkalan, 69162 \\ sriherawati@trunojoyo.ac.id
}

Dikirim 30 Maret 2016, Diterima 16 April 2016

\begin{abstract}
Abstrak - Peramalan kunjungan wisatawan mancanegara (wisman) sangat penting bagi pemerintah dan industri, karena peramalan menjadi dasar dalam perencanaan kebijakan yang efektif. Penelitian ini menggunakan Generalized Regression Neural Network (GRNN) untuk meramalkan kunjungan wisman menurut 19 pintu masuk utama dan kebangsaan, seperti: Ngurah Rai, Soekarno-Hatta, Batam, Tanjung Uban, Polonia, Juanda, Husein Sastranegara, Tanjung Balai Karimun, Tanjung Pinang, Tanjung Priok, Adi Sucipto, Minangkabau, Entikong, Adi Sumarmo, Sultan Syarif Kasim II, Sepinggan, Sam Ratulangi, Bandara Internasional Lombok, dan Makassar. GRNN memiliki kelebihan tidak memerlukan estimasi jumlah bobot jaringan untuk mendapatkan arsitektur jaringan optimal, sehingga tidak memerlukan pengaturan parameter bebas. Uji coba penelitian dilakukan dengan menggunakan spread dari 0,1 sampai 1,0. Hasil uji coba menunjukkan bahwa kinerja Peramalan terbaik dengan menggunakan spread 0,1 baik untuk data latih maupun data uji.
\end{abstract}

Kata kunci - Peramalan, Kunjungan wisman, Generalized regression neural network.

Abstract - Forecasting tourism demand are very important for the government and industry, as forecasting the basis for effective policy planning. This research is using Generalized Regression Neural Network (GRNN) to forecasting tourism demand according 19 the main entrance and nationality, such as: Ngurah Rai, SoekarnoHatta, Batam, Tanjung Uban, Polonia, Juanda, Husein Sastranegara, Tanjung Balai Karimun, Tanjung Pinang, Tanjung Priok, Adi Sucipto, Minangkabau, Entikong, Adi Sumarmo, Sultan Syarif Kasim II, Sepinggan, Sam Ratulangi International Airport Lombok, and Makassar. GRNN has advantages not require the estimated number of network weights to get optimal network architecture, so it does not require setting parameters. Research trial conducted using a spread of 0.1 to 1.0 . The experimental results show that the best forecasting performance with spread 0,1 for training and testing data.

Keywords - Forecasting, Tourism demand, Generalized regression neural network.

\section{PENDAHULUAN}

Sektor pariwisata sangat cepat berkembang seiring dengan pertumbuhan negara-negara di dunia. Sektor pariwisata merupakan salah satu sumber penerimaan devisa negara khususnya bidang ekonomi. Salah satu faktor penentu perkembangan pariwisata adalah banyaknya kunjungan wisatawan, baik wisatawan nusantara maupun mancanegara. Negara Indonesia merupakan salah satu tujuan utama kunjungan wisatawan mancanegara (wisman). Pada tahun 2014, data kunjungan terbanyak wisman mengunjungi Bali dengan total $39.80 \%$ terhadap wisatawan nusantara [1]. Selain itu, perkembangan pariwisata juga berhubungan dengan keputusan untuk sektor publik dan swasta, seperti: infrastruktur, transportasi [2], akomodasi [3], promosi, dan layanan lainnya [4]. Oleh karena itu, pemerintah dan industri membutuhkan peramalan akurat dari kunjungan wisman terebut. Peramalan dibutuhkan untuk perencanaan kebijakan yang efektif [5].

Penelitian sebelumnya tentang peramalan kunjungan wisatawan dilakukan oleh $\mathrm{Chu}$ dengan mengintegrasikan ARMA (p,d,q) (ARFIMA) [6]. Hasil peramalan baik ketika data cenderung linear. Namun, ARMA tidak cocok untuk sebagian besar permasalahan yang bersifat nonlinear [7]. Kemudian, Ticknor menggunakan jaringan syaraf tiruan (JST) untuk pemodelan non linear [8]. Selain itu, JST memiliki kemampuan adaptasi dan pembelajaran yang baik.

Salah satu jenis jaringan syaraf tiruan adalah Generalized Regression Neural Network (GRNN). Peramalan dengan menggunakan GRNN telah digunakan untuk memecahkan beberapa permasalahan, seperti: tingkat pencemaran udara [9] dan Indeks harga saham gabungan [10]. GRNN 
memiliki kelebihan tidak memerlukan estimasi jumlah bobot jaringan untuk mendapatkan arsitektur jaringan optimal, sehingga tidak memerlukan pengaturan parameter bebas. Selain itu, proses pembelajaran cepat dalam memberikan pemetaan dari satu bagian titik sampel ke titik lainnya [11]. Namun, peramalan yang menggunakan permasalahan kunjungan wisman belum ada yang melakukannya. Oleh karena itu, penelitian ini menggunakan GRNN untuk peramalan kunjungan wisman.

\section{KAJIAN PUSTAKA}

\section{A. Peramalan Tine Series}

Data time series merupakan sekumpulan data berdasarkan interval tertentu, seperti: harian, mingguan, bulanan, dan tahunan. Peramalan merupakan upaya untuk memprediksi kejadian yang akan datang. Peramalan memililki dua sifat yaitu berdasarkan pada data yang sudah ada (kuantitatif) dan berdasarkan pendapat para pakar (kualitatif).

Salah satu jenis peramalan kuantitatif menggunakan model time series. Peramalan data time series adalah meramalkan nilai yang akan datang berdasarkan data masa lalu pada periode tertentu. Peramalan ini dilakukan dengan memperhatikan pola deret waktu antara lain [12].

- Trend, pola deret waktu memiliki kecenderungan arah data untuk jangka panjang. Trend memiliki tiga jenis yaitu:

○ Trend linear, plot deret waktu yang mendekati garis lurus.

- Trend kuadratik, plot deret waktu yang berupa garis parabola.

- Trend eksponensial, plot deret waktu yang mengalami kenaikan dan penurunan yang cepat.

- Siklis, pola deret waktu memiliki fluktuasi / gelombang untuk waktu lebih dari satu tahun.

- Musiman, pola deret waktu memiliki fluktuasi secara periodik dalam jangka waktu satu tahun.

- Tak beraturan, pola deret waktu memiliki kejadian yang tidak terduga dan bersifat acak, namun data ini dapat mempengaruhi fluktuasi data deret waktu.

\section{B. Jaringan Syaraf Tiruan}

Jaringan syaraf tiruan (JST) merupakan upaya yang dilakukan manusia untuk memodelkan cara kerja sistem syaraf manusia dalam melakukan tugas tertentu [13]. Secara umum, JST mempunyai tiga lapisan yaitu lapisan masukan, lapisan tersembunyi, dan lapisan keluaran. Setiap lapisan dihubungkan melalui neuronneuron.

JST memerlukan proses pembelajaran dalam meniru sistem syaraf tersebut yang dibagi menjadi dua yaitu.

- Supervised learning, proses pembelajaran yang memerlukan pengawasan. JST memerlukan pelatihan untuk dapat memetakan sekumpulan sampel masukan dan keluaran, sehingga hasil diperoleh dengan tingkat akurasi yang tinggi.

- Unsupervised learning, proses pembelajaran yang tidak memerlukan pengawasan. Jenis jaringan tidak memerlukan sampel masukan dan keluaran untuk dipelajari. Jaringan ini hanya memiliki dua lapisan yaitu lapisan masukan dan lapisan kompetitif.

\section{Generalized Regression Neural Network (GRNN)}

Generalized regression neural networks (GRNN) merupakan salah satu jenis jaringan syaraf tiruan. GRNN adalah metode modifikasi dari radial basis function neural network (RBFNN). Pertama kali, GRNN diperkenalkan oleh Specht sebagai jaringan berbasis memori yang meramalkan variabel continue[14]. Arsitektur pada GRNN terdiri dari empat layer yaitu layer masukan, layer basis radial atau layer tersembunyi, layer penggabungan, dan layer keluaran [15].

Dalam proses pembelajaran, GRNN memerlukan penentuan tiga parameter yaitu spread, fungsi aktivasi, dan jumlah pola. Konvergen jaringan akan dilakukan sangat cepat, karena jaringan tidak memerlukan prosedur iterasi [16]. Nilai spread optimal ditentukan dengan trial dan error, serta harus lebih kecil dari jarak rata-rata antara vector masukan [17]. Sementara fungsi aktivasi biasanya menggunakan fungsi sigmoid, baik biner atau bipolar.

Salah satu jenis penafsiran GRNN dengan menggunakan analisis visual. Analisis ini dilakukan dengan mengukur hubungan variabel masukan dan variabel keluaran. Analisis variabel keluaran yaitu penghitungan akurasi peramalan dengan menggunakan Mean Squared Error (MSE) dan Root Mean Squared Error (RMSE). MSE ditunjukkan pada Equation 1 dan RMSE ditunjukkan pada Equation 2. A menyatakan data aktual untuk waktu ke-t, $F_{t}$ menyatakan data hasil peramalan untuk waktu ke-t, dan n menyatakan jumlah data yang diramalkan.

$$
\begin{gathered}
\text { MSE }=\frac{1}{n} \sum_{t !}^{n} \\
\text { RMSE }=\sqrt{\frac{1}{n} \sum_{t=1}^{n}}
\end{gathered}
$$
[10]

Algoritma GRNN dapat dijelaskan sebagai berikut

1. Pencarian jarak data ke-i dengan data ke-j $\left(D_{i j}\right)$ seperti pada Equation 3, dimana i,j $=1,2,3, \ldots, \mathrm{q}$.

$$
D_{i j}=\sqrt{\sum_{i=1}^{q}\left(p_{i}-i\right.}
$$

2. Mencari nilai $a_{i j}$ yaitu hasil aktivasi dengan fungsi radial dari jarak data dikalikan bias. Nilai $\mathrm{a}_{\mathrm{ij}}$ ditunjukkan pada Equation 4. 


$$
a_{i j}=e^{-\left(\tilde{E}_{1}+D_{i j}\right)^{2}}
$$

Dimana,

$$
b 1=\frac{0,8326}{\text { spread }}
$$

3. Mencari nilai bobot lapisan dan bobot bias lapisan untuk menghasilkan keluaran.

4. Melakukan perbandingan antara hasil keluran dengan data aktual, baik untuk data pelatihan maupun pengujian.

\section{METODOLOGI PENELITIAN}

Metodologi penelitian dilakukan seperti pada Gambar 1.

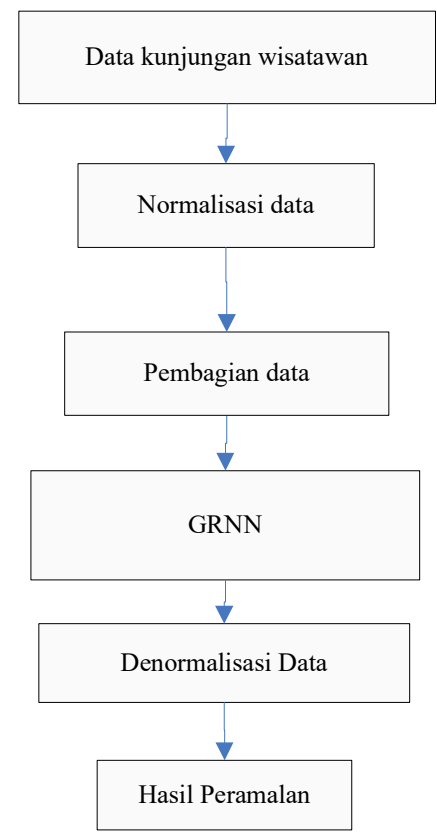

Gambar 1. Metodologi Penelitian

Berdasarkan Gambar 1, dapat dijelaskan bahwa tahapan pertama penelitian dengan mengumpulkan data kunjungan wisatawan mancanegara. Data penelitian berasal dari data sekunder Pusdatin Kemenparekraf dan Badan Pusat Statistika (BPS) Republik Indonesia. Data sekunder tersebut adalah banyaknya kunjungan wisatawan mancanegara perbulan ke Indonesia menurut 19 pintu masuk utama dan kebangsaan, seperti: Ngurah Rai, Soekarno-Hatta, Batam, Tanjung Uban, Polonia, Juanda, Husein Sastranegara, Tanjung Balai Karimun, Tanjung Pinang, Tanjung Priok, Adi Sucipto, Minangkabau, Entikong, Adi Sumarmo, Sultan Syarif Kasim II, Sepinggan, Sam Ratulangi, Bandara Internasional Lombok, dan Makassar. Data dimulai dari Januari 2009 sampai dengan Desember 2014 sebanyak 72 data. Kemudian, data penelitian dibagi menjadi dua bagian yaitu data latih dan data uji. Data latih menggunakan data sebesar $70 \%$, sedangkan data uji menggunakan data sebesar $30 \%$.

Tahapan kedua adalah melakukan normalisasi data. Normalisasi data menggunakan sigmoid biner, sehingga data aktual dinormalisasi menjadi data dengan jangkauan antara 0,1 sampai 0,9. Kemudian data hasil normalisasi dibagi menjadi dua bagian yaitu data pelatihan dan pengujian. Tahapan selanjutnya menggunakan GRNN untuk mendapatkan hasil peramalan, baik untuk data latih maupun data uji. Langkah terakhir melakukan denormalisasi hasil keluaran GRNN agar menjadi angka sebenarnya. Untuk mengukur kinerja peramalan, penelitian ini menggunakan Equation 1 dan 2.

\section{HASIL DAN PEMBAHASAN}

Langkah awal penelitian peramalan kunjungan wisman menggunakan GRNN dengan membuat plot data runtun waktu kunjungan wisman ke Indonesia. Plot data tersebut dibutuhkan untuk melihat pola data kunjungan seperti pada Gambar 2.

Setelah itu, peramalan kunjungan wisatawan dilakukan sesuai dengan metodologi penelitian sebelumnya. Variasi spread menggunakan jangkauan dari 0,1 sampai 1,0. Perbandingan kinerja peramalan kunjungan wisman ditunjukkan pada Tabel 1.

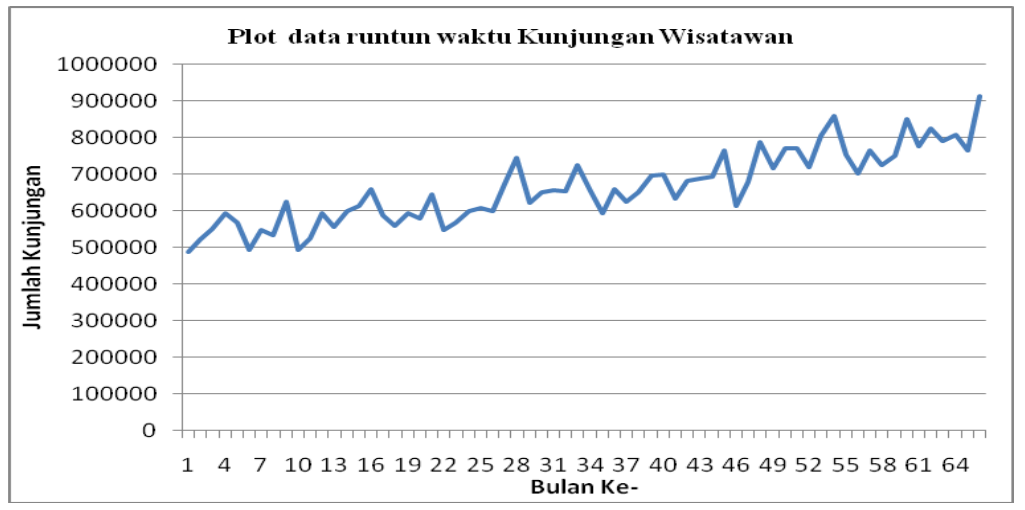

Gambar 2. Grafik plot data runtun waktu kunjungan wisatawan 
Tabel 1. Perbandingan hasil peramalan dengan variasi spread

\begin{tabular}{ccccc}
\hline \multirow{2}{*}{ Spread } & \multicolumn{2}{c}{ MSE } & \multicolumn{2}{c}{ RMSE } \\
\cline { 2 - 5 } & data latih & data uji & $\begin{array}{c}\text { data } \\
\text { latih }\end{array}$ & data uji \\
\hline 0,1 & 0,00732775 & 0,025445 & 0,085602 & 0,159513 \\
0,2 & 0,01139909 & 0,031543 & 0,106767 & 0,177605 \\
0,3 & 0,01377744 & 0,038053 & 0,117377 & 0,195071 \\
0,4 & 0,01592623 & 0,044702 & 0,126199 & 0,211428 \\
0,5 & 0,01763330 & 0,050390 & 0,132790 & 0,224476 \\
0,6 & 0,01888229 & 0,054689 & 0,132790 & 0,233857 \\
0,7 & 0,01977733 & 0,057791 & 0,140632 & 0,240397 \\
0,8 & 0,02042387 & 0,060021 & 0,142912 & 0,244991 \\
0,9 & 0,02089952 & 0,061648 & 0,144567 & 0,248290 \\
1,0 & 0,02125676 & 0,062859 & 0,145797 & 0,250717 \\
\hline
\end{tabular}

Berdasarkan Tabel 1 dapat dilihat bahwa kinerja hasil peramalan terbaik dengan menggunakan spread 0,1 . Nilai MSE terkecil diperoleh sebesar 0,00732775 untuk data latih dan data uji sebesar 0,025445. Sementara itu, nilai RMSE terkecil diperoleh sebesar 0,085602 untuk data latih dan data uji sebesar 0,159513 .

Gambar 3 menunjukkan grafik perbandingan hasil data pelatihan peramalan dengan data aktual, sedangkan Gambar 4 menunjukkan grafik perbandingan hasil data pengujian peramalan dengan data aktual. Grafik tersebut menggunakan peramalan dengan spread 0,1. Perbandingan menunjukkan kinerja yang cukup baik yang dilihat dari kedekatannya dengan data aktual.

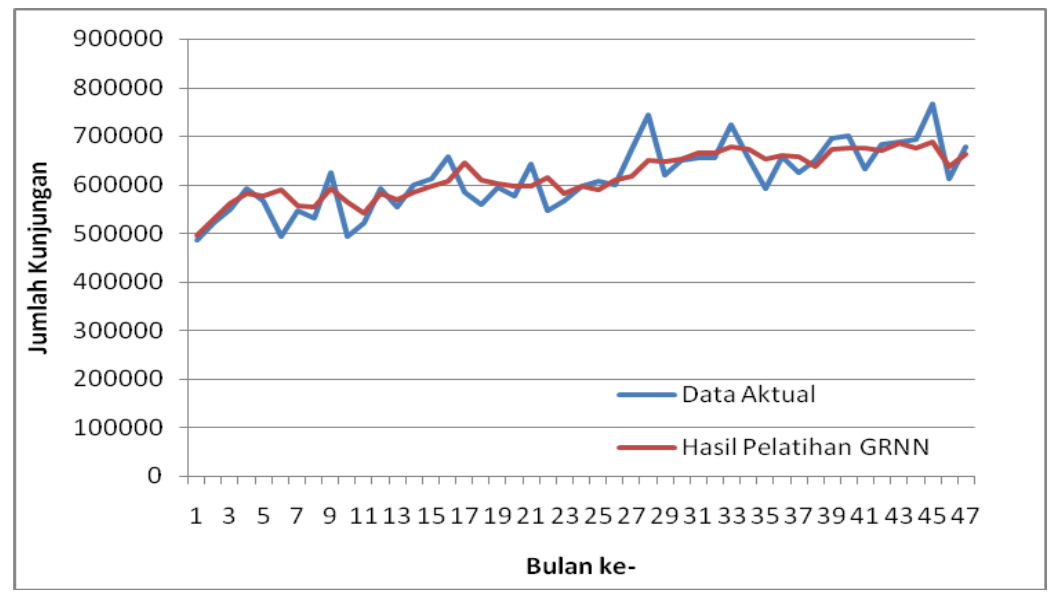

Gambar 3. Grafik hasil pelatihan kunjungan wisatawan menggunakan GRNN dengan data aktual

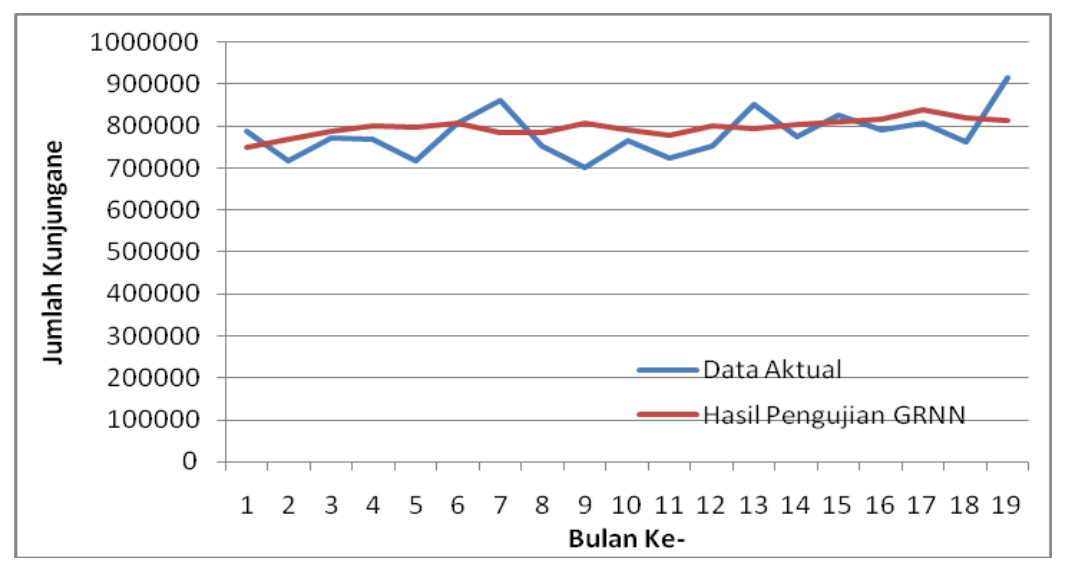

Gambar 4. Grafik hasil pengujian kunjungan wisatawan menggunakan GRNN dengan data aktual

\section{PENUTUP}

\section{A. Kesimpulan}

Dari hasil uji coba dapat disimpulkan bahwa peramalan kunjungan wisman dalam penelitian ini menghasilkan kinerja yang baik. Kinerja terbaik diperoleh dengan menggunakan spread 0,1. Nilai MSE terkecil diperoleh sebesar 0,00732775 untuk data latih dan data uji sebesar 0,025445, sedangkan 
nilai RMSE terkecil sebesar 0,085602 untuk data latih dan data uji sebesar 0,159513 .

\section{B. Saran}

Penelitian kunjungan wisman menggunakan GRNN masih mungkin untuk dikembangkan lebih lanjut. Pengembangan dimaksudkan untuk meningkatkan akurasi hasil peramalan melalui integrasi dengan metode lainnya.

\section{DAFTAR PUSTAKA}

[1] Rukini, P. S. Arini and E. Nawangsih, "Peramalan Jumlah Kunjungan Wisatawan Mancanegara (Wisman) ke Bali Tahun 2019: Metode ARIMA," pp. 136-141, 2015

[2] D. C. Wu, G. Li, and H. Song "Economic Analysis Of Tourism Consumption Dynamics: A Time-varying Parameter Demand System Approach," Annals of Tourism Reseach., vol. 39, no. 2, pp. 667-685, 2012.

[3] S. K. Lee, "Quality differentiation and conditional spatial price competition among hotels," Tour. Manag., vol. 46, pp. 114-122, 2015.

[4] F. Chu, "Using a logistic growth regression model to forecast the demand for tourism in Las Vegas," TMP, vol. 12, pp. 62-67, 2014.

[5] P. Pai, K. Hung, and K. Lin. "Expert Systems with Applications Tourism demand forecasting using novel hybrid system: clustering center," Expert Systems with applications Vol. 41, No. 8, pp. 3691 -3702, 2014.

[6] F. L. Chu, "A fractionally integrated autoregressive moving average approach to forecasting tourism demand, “ Tourism Management Vol. 29, pp. 79-88, 2008 .

[7] M. Khasei, M. Bijari, and G. A. R. Ardali, "Improvement of auto-regression integrated moving average models using fuzzy logic and artificial neural network (ANNs), “ Neurocomputing Vol. 72, No.4, pp. 956-967, 2009.

[8] J. L. Ticknor, “ A Bayesian regularized artificial neural network for stock market forecasting," Expert Systems with Applications Vol. 40, No. 14, pp. 5501 5506, 2013.

[9] B. Warsito, A. Rusgiyono, and M. A. Amirillah, "Pemodelan General Regression Neural Network untuk Prediksi Tingkat Pencemaran Udara Kota Semarang, “ Media Statistika, Vol 1, No. 1, pp. 43-51, 2008 .

[10] L. W. Adnyani, and Subanar, " General Regression Neural Network (GRNN) pada Peramalan Kurs Dolar dan Indeks Harga Saham Gabungan (IHSG)," Faktor Exacta, Vol. 8.No. 2, pp. 137-144, 2015.

[11] S. R. Patil, and V. N. Ghate, "Ageneralized Regression Neural Network Based on Soft Sensor for Multicomponent Distillation Column," International Journal of Computer and Communication Engineering Vol. 4, No. 6, pp. 371-378, 2015.

[12] S. Santoso, Business Forecasting: Metode Peramalan Bisnis Masa Kini dengan Minitab dan SPSS. Elek Media Komputindo, Jakarta, 2009.
[13] Suyanto, Artificial Intelligence : Searching, Reasoning,Planning, Learning. Informatika Bandung, 2011.

[14] D. F. Specht, " A General Regression Neural Network," IEEE Transaction on Neural Network, Vol. 2, No. 6, pp. 568-576, 1991.

[15] M. Theodosiou, "Disaggregation \& Aggregation of Time Series Components: A Hybrid Forecasting Approach Using Generalized Regression Neural Networks and Theta Method," Neurocomputing 74, pp. 896-905, 2011.

[16] N. Djarfour, J. Ferahtia, F. Babaia, K. Baddari, E. Said, and M. Farfour, "Seismic noise filtering based on Generalized Regression Neural Networks," Computers \& Geosciences, Vol. 69, pp. 1-9, 2014.

[17] L. Chaofeng, C. B. Alan, W. Xiaojun, "Blind image quality assessment using a general regression neural network, “IEEE Trans. Neural Network, Vol. 22, pp. 793-799, 2011. 